\title{
ANGELA PRYSTHON \\ Do Terceiro Cinema ao cinema periférico Estéticas contemporâneas e cultura mundial
}

Resumo:

Este artigo pretende explorar as possibilidades de conexão entre o campo dos Estudos Culturais e o Cinema contemporâneo. A intenção é tanto verificar como a própria configuração do cinema (especialmente aqueles filmes produzidos na periferia mundial ou, em termos históricos, aquilo que ainda pode ser chamado de Terceiro Cinema) demanda o olhar interdisciplinar que caracteriza a empresa metodológica dos Estudos Culturais, como também encontrar em alguns traços comuns que definem o "cinema periférico" novos desafios e inquietações para a teoria da cultura contemporânea.

Palavras-chave: Estudos culturais; terceiro cinema; cultura contemporânea.

Abstract:

This article explores the possibilities of connection between the field of Cultural Studies and contemporary cinema. The purpose is to verify how the very configuration of cinema (specially those films produced in the world periphery - or more specifically what we could still call "Third Cinema") demands the interdisciplinary approach that characterizes Cultural Studies. But there is also the intention to find in the common traces that define peripheral cinema new challenges and preoccupations for contemporary cultural theory.

Keywords: Cultural Studies - Third Cinema - Contemporary Culture 
ste artigo tem como propósito apresentar a emergência de um foco periférico e subalterno no
cinema contemporâneo. Para isso, faz-se necessário demonstrar o trajeto do chamado
Terceiro Cinema nos anos 60 até a sua versão mais recente, que é noção de cinema periférico. A intenção é identificar as estéticas cinematográficas que simultaneamente articulam aspectos tradicionais e modernos, que negociam de modo extremamente complexo com conceitos cosmopolitas pós-modernos e nacionalismos autoexóticos. O sucesso recente de algumas cinematografias nacionais ou regionais (caso, por exemplo, do cinema iraniano e do asiático na década de 1990, ou do cinema latino-americano nos últimos cinco anos) faz com que lembremos muito vividamente dos anos sessenta e dos movimentos culturais que refletiam as profundas transformações pelas quais o mundo estava passando na época. Das novas ondas aos novos cinemas, passando pelos neo-realismos e cinemas livres, especialmente a partir do final dos anos 50, o cinema (e o estudo do cinema também pode ser incluído numa percepção mais abrangente do fenômeno) passou a ser fortemente marcado pela política, pelo engajamento, pela dissidência, pela opção pelas "margens". Desde uma personagem como a adolescente da classe operária inglesa Jo (Rita Tushingham), de Um gosto de mel (Tony Richardson, 1961 - Inglaterra), que engravida de um marinheiro negro e emula um "casamento" com um jovem estudante gay, até o judeu Ariel (Daniel Hendler), de O abraço partido (Daniel Burman, 2004 - Argentina), com a sua vontade de se tornar "polaco", passando pela denúncia dos filmes mais explicitamente políticos e chegando à representação da política das minorias contemporâneas. Num certo sentido, ao longo de todas essas décadas, o conceito de Terceiro Mundo e o radicalismo associado a ele foram sendo transpostos ao cinema (alguns cineastas e teóricos ainda usam o termo "Terceiro Cinema" para se referir ao cinema dos paísesnão-desenvolvidos ou ao cinema feito às margens da estética hollywoodiana).

Entretanto, é evidente que o atual interesse pelas cinematografias periféricas não pode ser completamente equacionado ao espírito da contracultura e do cinema dos anos sessenta. É importante sublinhar o que há de distinto na inclinação corrente pelos discursos identitários no cinema contemporâneo. Ou seja, para entender o cinema contemporâneo, faz-se necessário relacionar aspectos históricos que consolidaram a idéia de Terceiro Mundo e os fenômenos culturais que fizeram parte desse contexto. Também se faz relevante delinear os movimentos que refletiam as profundas transformações pelas quais o mundo estava passando e que por sua vez também definiam o espírito da época de modo paradigmático. Destacamos a influência que o conceito de Terceiro Mundo teve para a construção dos imaginários cinematográficos (não apenas os cinematográficos, é evidente). 
O termo Terceiro Mundo começou a ser utilizado por demógrafos e geógrafos franceses nos anos 50 como a outra peça no quebra-cabeças do mundo pós- Segunda Guerra Mundial, em relação a um Primeiro Mundo capitalista e ocidental e um Segundo Mundo socialista. Nesta época, talvez com o valor de eufemismo, ele substitui a idéia mais difusa, menos organizada e mais traumática de "países pobres". A partir das lutas de independência das colônias européias na África e na Ásia, o termo adquire certo prestígio. A unidade pretendida por ele traz, pois, em seu bojo, uma dimensão revolucionária. A dimensão de relevar as diferenças em prol de um ideal libertário legitimaria então a noção de Terceiro Mundo. Na conferência de Bandung, em 1955, o termo teve a sua primeira expressão política oficial, quando se reuniram todas as nações "não-alinhadas" - ou seja, nem ao Primeiro Mundo, nem ao Segundo. (HARLOW,1987)

A concepção libertária de Terceiro Mundo foi favorecida por paradigmas apresentados nos séculos e, principalmente, nas décadas anteriores: pelo existencialismo, pelas leituras que o Terceiro Mundo fez de Sartre, pelo próprio declínio do humanismo (JAMESON, 1984). Um modelo estabelecido por Frantz Fanon, em Les damnés de la terre, de 1961, obra precursora, em certa medida, da unidade, do "chamamento" ao Terceiro Mundo, e sem dúvida uma base importante para o "espírito de 1968". Um chamamento de luta, de violência, de uma relativa rejeição dos cânones "ocidentais": uma tentativa de livrar-se de certas concepções de cultura, sociedade, história, política... O impacto da visão de Fanon é notável por sua disseminação em todo(s) o(s) mundo(s) (especialmente no "Terceiro", obviamente). A sua influência deve-se tanto à sua teorização sobre descolonização e violência, à sua apreensão do espírito da época e à denúncia antiimperialista que ele inspira, como à sua capacidade de pensar essa descolonização como construção violenta sim, mas com fins utópicos.

Uma provável unidade terceiro mundista possibilitaria a atuação destacada do Terceiro Mundo no "mundo", na ordem internacional. A voz coletiva desse legado de pobreza e exploração se fez ouvir mais forte durante os anos 60 e com as revoluções vencedoras e também as fracassadas que assustam e maravilham este "mundo". Desde o pós-guerra, a Nouvelle Vague francesa revolucionando esteticamente o cinema e o neo-realismo italiano e o Free Cinema Britânico mostrando uma Europa quase terceiro-mundista, o movimento norte-americano contra a Guerra do Vietnã,os hippies americanos "instituindo" uma contra-cultura. O "mundo" viu Cuba, as guerrilhas, Che, a Revolução Cultural chinesa, viu, finalmente, os estudantes em Maio de 1968: a cultura mundial acabou sendo influenciada e influenciando os movimentos políticos simultaneamente. 
Ou seja, o conceito de Terceiro-Mundo serve a partir dos anos 60 - para além das delimitaç̃es eufemísticas e conservadoras da geografia contemporânea - para estabelecer uma unidade de cunho libertário e idealista. Os processos de descolonização, de conscientização social e de luta política desencadeados no globo ao longo deste período (deste estendido 1968) não se esgotam em si mesmos: eles fazem parte da grande crise da modernidade que implica também numa reorganização (ou desorganização) cultural em todos os cantos do globo. Reafirmamos, então, que uma das mais diretas e evidentes influências da consciência terceiro-mundista (e todas as suas implicações) foi a própria constituição da idéia de Terceiro Cinema.

De acordo com a idéia de transformação da sociedade pela conscientização trazida à tona pelos ideais terceiro-mundistas, os principais temas dos filmes do Terceiro Cinema vão ser a pobreza, a opressão social, a violência urbana das metrópoles inchadas e miseráveis, a recuperação da história dos povos colonizados e oprimidos e a constituição das nações. Os praticantes do Terceiro Cinema recusam adotar um modelo único de estratégias formais ou transformar-se em um "estilo", embora isto não tenha significado que eles estivessem alheios ao cinema mundial e à idéia de um modelo, se aberto, ao menos em linhas gerais unificador.

Ou seja, além de buscar os temas nas esferas marginalizadas da sociedade, estes cineastas demonstram laços estilísticos estreitos com o neo-realismo italiano e a Nouvelle Vague francesa. Tais influências vão ser sentidas em dois níveis principais: o neo-realismo italiano serve como proposta similar de abordagem formal que pode ser aproveitada por sua simplicidade, baixo custo e linguagem direta; e a Nouvelle Vague enquanto afirmação do "cinema de autor", o que possibilita a consolidação das linguagens individuais dos principais expoentes do movimento. A partir desses elementos, emerge um conjunto de procedimentos mais ou menos comuns à maioria dos diretores engajados na denúncia social.

Por um lado, técnicas abertas e simples (em contraste com sofisticação tecnológica do modelo de estúdios hollywoodianos), por outro, a veiculação de idéias complexas e revolucionárias, como a liberação terceiro-mundista, as teorias do subdesenvolvimento, etc. O Terceiro Cinema pode ser visto, assim, como um statement sobre o cosmopolitismo de duas vias: primeiro, como interpretação subalterna, terceiro-mundista, das últimas tendências estéticas européias (cosmopolitismo "à moda antiga") como o neo-realismo e a Nouvelle Vague. Segundo, como negação desse cosmopolitismo tradicional onde existe um Centro metropolitano definindo o que os povos subalternos devem fazer. 
No Terceiro Cinema, os destituídos são colocados no Centro. A atitude é de rebeldia e não apenas a rebeldia estética, mas a rebeldia política e de ação social.

É irrefutável que o Terceiro Cinema, que teve na América Latina seus primeiros e talvez mais eminentes cineastas e teóricos (Fernando Solanas e Octavio Getino na Argentina; Glauber Rocha no Brasil, Jorge Sanjinés na Bolívia) (DISSANAYAKE e GUNERATNE, 2003, 3), teve seu período áureo exatamente na mesma época em que o chamamento terceiro-mundista ecoava com mais força, ou seja, durante os anos 60, ou se preferirmos, durante esse longo 1968, ápice da contracultura e momento crucial de formação, prática e teorização de uma "estética geopolítica" (JAMESON, 1995). E assim como as utopias sessentoitistas foram definhando ao longo da década de 80, também a noção de Terceiro Cinema foi gradualmente perdendo lugar (tanto nas salas de exibição, como na própria pesquisa na área de cinema e audiovisual).

Os anos 80 foram quase definitivos para o "Terceiro-Mundismo" (para o conceito de Terceiro Mundo, para a estética terceira-mundista, para a prática revolucionária terceiro-mundista que restou dela). Primeiro porque foi a partir desta década que se questionou teoricamente com mais ênfase a validade do termo, justamente a partir dos Estudos Culturais e do pós-colonialismo. Também nos 80, começamos a assistir ao ocaso do Segundo Mundo (culminando na sua "dissolução" como Segundo Mundo, simbolizada pela queda do Muro de Berlim, em 1989). O não-alinhamento às grandes potências se esgotou como estratégia de resistência e oposição ideológica. Por isto também, a estética terceiro-mundista radical pereceu e outras "terceiras margens" foram buscadas, já que não parecia funcionar mais a apologia do oprimido. Talvez tenha acontecido a desilusão final do Terceiro Mundo como categoria unificada e indivisível:

The term Third World, post-colonial critics insist, was quite vague in encompassing within one uniform category vastly heterogeneous historical circumstances and in locking in fixed positions, structurally if not geographically, societies and populations that shifted with changing global relationships. (DIRLIK, 332) ${ }^{1}$

\footnotetext{
1 “O termo Terceiro Mundo, os críticos pós-coloniais insistem, era um tanto vago ao abarcar numa categoria uniforme circunstâncias históricas amplamente heterogêneas e ao colocar em posições estruturalmente fixas sociedades e populações que se deslocaram com as relações globais cambiantes".
} 
PERIFERIA - Volume 1. Número 1. 
Convergências contemporâneas nas margens

Se os anos 80 representaram uma espécie de vácuo para o Terceiro Cinema (e para a estética terceiro-mundista) como um todo, a segunda metade dos 90 significou a reemergência de muitas das questões ligadas ao imaginário político-social das décadas de 60 e 70 . Entretanto o que podemos chamar de "reinsurgência da periferia" ou "reencenação da subalternidade" se deu de maneira muito distinta do discurso engajado precedente.

Poderíamos dizer que, de maneira muito geral, os anos 80 foram um período no qual não parecia fazer parte do dominante cultural dos principais países "terceiro-mundistas" produtores de cinema (em especial a América Latina) a representação de aspectos políticos e sociais da periferia. A tematização das identidades nacionais e das realidades mais desoladoras foi quase que totalmente abandonada e quando ainda se insistia numa temática mais próxima àquela do Terceiro Cinema original, o resultado refletia uma espécie de esvaziamento. Contudo, a retomada representada pelos anos 90 representa menos uma drástica mudança e mais um gradual amadurecimento dos preceitos culturais (e até teóricos) anteriores. As próprias tendências acadêmicas mundiais rumo a uma valorização do ex-cêntrico, do periférico, do marginal (BHABHA, 1998) tiveram um efeito revigorante sobre os cinemas nacionais. Até mesmo os renovados paradigmas filosóficos e sociológicos trazidos à tona pelos Estudos Culturais e teorias pós-coloniais, embora de forma muito lateral e específica, contribuíram não apenas para o redespertar do interesse no agora chamado World Cinema, mas para revitalizar os instrumentos de leitura e recepção dos filmes.

Pois, se do ponto de vista teórico parece evidente que um dos elementos mais essenciais no campo cultural nas últimas décadas do século XX é o descentramento - em vários sentidos e não apenas no territorial (descentramento do sujeito e das identidades provocado pela fragmentação social, descentramento geográfico facilitado pelo desenvolvimento tecnológico e descentramento cultural favorecido pelas tendências multiculturalistas e pelos diálogos interculturais que se intensificam a partir da década de 80), o impacto da gama de processos que redimensiona o papel da periferia, das margens e do terceiro mundo na história e na teoria vai ser igualmente indiscutível no estabelecimento e consolidação de estéticas cinematográficas alternativas.

Os descentramentos (teóricos, estéticos e materiais) supõem também a dissolução de fronteiras, de heterogeneidade cultural, de interpenetração de discursos, de diálogo entre "mundos". Mundo tecnológico e mundo natural. "Primeiro" e “Terceiro" mundos. Global e local. Universal e regional. Metrópoles e aldeias. Ocidente e Oriente. Discursos “originais" e hibridismos. Cânones e 
margens. Territórios que se sobrepõem uns aos outros, interstícios constantemente ampliados. Um encontro, um diálogo tenso entre mundos que às vezes se opõem e às vezes se complementam. Uma política de diferenças vai sendo engendrada por meio de complexas negociações, sobreposições e deslocamentos culturais. Os descentramentos da sociedade contemporânea vão tendo, naturalmente, um forte impacto na maneira em como se vive, se pensa e se constrói a noção de diálogo intercultural. São complexos processos de "realinhamento de fronteiras" que afetam profundamente não apenas a produção cultural contemporânea, mas a forma de pensá-la, de analisá-la e catalogá-la.

O cinema periférico tem emergido nos últimos anos como uma espécie de moda cultural dos grandes centros. Está quase que automaticamente preservado o "direito de exibição" por essas "denominações de origem". Esse lugar de destaque - conquistado sobretudo a partir do final da década de 90 e início dos 2000 com filmes como O Balão Branco (Jafar, Panahi, 1995 - Irã,); Central do Brasil (Walter Salles, 1998 - Brasil), Amores Brutos (Alejandro González Iñarritú, 1999 - México), Nove Rainhas (Fabián Bielinsky, 1999 - Argentina), Amor à flor da Pele (Wong Kar-Wai, 2000 - Hong Kong) não é definido por uma unidade estética ou temática (embora possamos agrupar algumas recorrências, evidentemente, ao longo das duas últimas décadas), mas sim pela vaguíssima possibilidade de redelineamento da noção de Terceiro Cinema através do termo World Cinema e do conceito de multiculturalismo.

Entretanto, é possível enumerar e comentar (de modo talvez excessivamente panorâmico e superficial) algumas características do antes chamado Terceiro Cinema a partir dos anos 90. Começamos notando que há uma busca explícita pela inserção no mercado de cultura mundial. Tal inserção está, de certo modo, garantida pelo espírito do tempo, um momento bem propício no qual a cultura periférica não apenas passa a ser percebida pela cultura central, como passa a ser consumida na metrópole; o ponto em que a diferença cultural passa a ser encarada quase como estratégia de marketing. Caso, por exemplo, do cinema latino-americano que, ao final da década de 90 passa a ser rotulado de "Cinema Buena Onda" por certa imprensa internacional'2. Em alguns filmes e cineastas, fica evidente também a forte inclinação para o passado, numa tentativa explícita de rearticulação da tradição. Que muitas vezes parece ser o sinal de uma nostalgia, o sintoma de uma saudade cultural. Como também pode ser a explicitação de um diálogo dessa tradição com a modernidade, pode ser a subversão da idéia de identidade nacional tendo em vista um cosmopolitismo ex-cêntrico. No cinema

\footnotetext{
2 Várias revistas e veículos do mercado cultural europeu reúnem diretores de origem diversa como Fernando Meirelles, Pablo Trapero, Fabián Bielinsky, Walter Salles, etc, sob a égide de cinema Buena Onda. Buena Onda é também o nome de uma das produtoras associadas do filme Família Rodante (Argentina, 2004), de Pablo Trapero, entre outros.
} 
brasileiro, por exemplo, esta tendência vai ser bem marcada, considerando especialmente a herança da estética do cinema novo e as tentativas revisionistas da história recente do país. Esse cinema apresenta, num direto contraponto à cultura yuppie, consumista e frívola de um primeiro pósmodernismo dos anos 80, uma tentativa de rearticulação com a tradição, e afirma constantemente as narrativas da nação, mas freqüentemente procurando subverter noções fechadas sobre identidade. $\mathrm{O}$ passado, a tradição, a História passam a ser material fundamental dessa produção cinematográfica.

Tais opções revelam uma espécie de segundo pós-modernismo cinematográfico ligado ao Terceiro Cinema, em oposição ao preexistente nos anos 80 (marcado pela superficialidade, pelo artifício, pela influência norte-americana). Um pós-modernismo regido pelos princípios de "recuperação", de "reciclagem", de "retomada" da tradição, da história e de um certo autoexotismo em oposição ao gosto pelo estrangeiro, pelo cosmopolitismo tradicional, pelo discurso internacionalista do pós-modernismo da década anterior. Nesse sentido, vão sendo definidas modernidades periféricas. O caso do cinema asiático é especialmente notável pela sofisticação visual com que essas versões alternativas da modernidade são apresentadas. Pensemos em filmes como Oldboy (Chanwook Park, 2005) ou O Gosto da Melancia (Tsai Ming-Liam, 2004) que, sem a urgência de rejeitar os cânones narrativos hegemônicos e populares, pelo contrário, dialogando muito diretamente com eles (no caso de Park, os filmes de aventura e ação, o imaginário pós-moderno ocidental; no caso de Ming-Liam, os musicais), vão estabelecendo novos paradigmas estéticos - simultaneamente globais e locais - e redefinindo de modo muito peculiar a idéia de pós-moderno.

Talvez a característica mais relevante do cinema periférico contemporâneo seja justamente a maneira como ele se volta para a documentação do pequeno, do marginal, do periférico, mesmo que para isso se utilize de técnicas e formas de expressão (às vezes até equipe de produção) de origem central, metropolitana, hegemônica, marcando assim uma distância enorme da tradição cinematográfica terceiro-mundista dos anos sessenta. Ou seja, a diferença, a história e a identidade periféricas tal como representadas pelo cinema contemporâneo tornam-se peças constitutivas da tentativa de integração ao modelo capitalista global. A idéia de articulação periférica e da identidade nacional com uma roupagem "globalizada" nesses filmes não só faz parte do establishment, como mostra de forma muito clara o funcionamento do mercado cultural globalizado.

Também a cidade desenhada pelo "novo" Terceiro Cinema pouco tem a ver com os clichês recorrentes (um exemplo muito interessante está na forma como Buenos Aires é representada no filme Felizes Juntos, do chinês Wong Kar Wai, que mostra um casal gay, originário de Hong Kong, em férias em Buenos Aires. Depois de gastar todo o dinheiro que tinham, passam por uma série de 
PERIFERIA - Volume 1. Número 1.

contratempos que os impede de voltar para a Ásia. A idéia parece ter sido subverter o olhar, mostrar uma tradução asiática da América Latina., assim tornando-se um dos exemplos mais bem acabados de diálogo intercultural do cinema recente). E é precisamente através de imagens urbanas pouco usuais e da opção estética pelo pequeno, pelo detalhe, pelo periférico que os filmes constroem uma representação alternativa, mais plena de nuances e mais complexa do mundo contemporâneo. Remontando, em certa medida, à temática do Terceiro Cinema original (desvalidos, subalternos, excluídos), porém sem deixar de privilegiar os aspectos técnicos do cinema (a maior parte da produção contemporânea periférica tem imagem e som comparáveis às grandes produções do cinema mainstream), o cinema periférico contemporâneo estaria atualizando o discurso do terceiro-mundismo (ou seja, uma maneira pós-moderna de falar da subalternidade, do periférico) retirando dele o tom politicamente engajado explícito, a "estética da fome" e a técnica propositadamente limitada.

Enfim, a partir dessas notas bem gerais sobre o Terceiro Cinema -ou cinema periférico contemporâneo -, vislumbramos não somente a vaga delimitação de uma estética cinematográfica contemporânea - uma estética da identidade e da diferença - , mas uma espécie de dominante cultural que poderia ser diretamente associado a outras esferas da cultura. O cinema tem sido, aliás, o cerne de uma significativa parcela das publicações recentes na área de Estudos Culturais (como, por exemplo, SHIEL e FIZTMAURICE, 2001; BARBER, 2002; VITALI e WILLEMEN, 2006; GRANT e KUHN, 2006; BADLEY, PALMER, e SCHNEIDER, 2006, entre muitos outros). Há, portanto, um notável interesse das teorias da cultura em dar conta dessa produção cinematográfica, reconhecendo nela simultaneamente um corpus relevante de objetos materiais do contemporâneo (passíveis de análise formal) e um campo de representações (e muitas vezes também de práticas) de subversão e resistência subculturais.

Angela Prysthon é Doutora em Teoria Crítica e Estudos Hispânicos pela Universidade de Nottingham, Reino Unido e Professora do Programa de pós-graduação em Comunicação da Universidade Federal de Pernambuco. 
PERIFERIA - Volume 1. Número 1.

Referências Bibliográficas

BADLEY, Linda, PALMER, R. Barton e SCHNEIDER, Steven Jay (eds). Traditions in World Cinema. Edimburgo: Edinburgh University Press, 2006.

BARBER, Stephen. Projected Cities. Cinema and Urban Space. Londres: Reaktion Books, 2002.

BHABHA, Homi K.. O local da cultura. Belo Horizonte: Editora da UFMG, 1998.

DIRLIK, Arif. "The Postcolonial Aura: Third World Criticism in the Age of Global Capitalism", Critical Inquiry 20 (1994), pp.328-356.

DISSANAYAKE, Wimal e GUNERATNE, Anthony (orgs). Rethinking Third Cinema. Londres/Nova York: Routledge 2003.

GRANT, Catherine e KUHN, Annette (eds). Screening World Cinema. Londres/Nova York: Routledge, 2006.

HARLOW, Barbara. Resistance Literature. Londres/Nova York: Methuen, 1987.

JAMESON, Fredric. The Geopolitical Aesthetic. Cinema and Space in the World System. Londres/ Bloomington: British Film Institute / Indiana University Press, 1995.

"Periodizing the 60s". The 60s without apology. Minneapolis: University of Minnesota Press, 1984.

SHOHAT, Ella e STAM, Robert. Multiculturalismo, cine y medios de comunicación. Crítica del pensamiento eurocéntrico. Buenos Aires: Paidós, 2002.

VITALI, Valentina e WILLEMEN, Paul (orgs.). Theorising National Cinema. Londres: British Film Institute, 2006. 